\title{
Colors and Flavors: Adding Joy to Pediatric Dentistry- A Cross-sectional Study
}

\author{
1Jyotirmayee Dalai, ${ }^{2} \mathrm{HN}$ Subhadra, ${ }^{3}$ Vikesh Sisodia
}

\begin{abstract}
Introduction: Color is one of the most instantaneous methods of conveying messages and meanings. It has been studied widely from philosophical, biological, anthropological and psychological perspectives over the course of time. Recently, the correlation between colors and emotions and their effect on the work settings is being studied. The importance of appropriate use of colors in various hospital settings is studied. Colors need to be incorporated not only in the dental setups but in the armamentarium and material that are going to be in a close vision of the child and are going to be delivered in the mouth.
\end{abstract}

Aim: To assess the preference of children and parents towards conventional, colored and flavored restorative materials, appliances, and the armamentarium required for it.

\section{Objectives:}

- To assess the preference of children in the age group of 6 to 12 years for various colors in restorative materials, appliances, and the armamentarium.

- To assess the preference of parents towards various colors in restorative materials, appliances, and the armamentarium.

Materials and methodology: The study was carried out in the Department of Pediatric and Preventive Dentistry, Yerala Dental College and Hospital, Kharghar, India. Sixty children in the age group of 6 to 12 years reporting to the OPD along with their parents, formed the sample for this study. The preference of children and their parents for the various material, armamentarium, and appliances delivered to a child was evaluated using a study tool. The study tool comprised of a separate questionnaire for the parents and the children. The questionnaire was aided with a power-point presentation. Physical demonstration of material was done wherever flavored materials were being evaluated

Statistical analysis: Data analysis was done using windows based MedCalcStatistical Software version 13.3.1 (MedCalc Software bvba, Ostend, Belgium; http://www.medcalc.org; 2014).

The following statistics were applied:

- Means: Average age of participants.

- Proportions: Most preferred choice.

\footnotetext{
${ }^{1}$ Lecturer, ${ }^{2,3}$ Reader

${ }^{1}$ Dr DY Patil Dental College \& Hospital, Dr DY Patil Vidyapeth, Pune, Maharashtra, India

${ }^{2-3}$ Yerala Dental College and Hospital, Navi Mumbai, Maharashtra, India
}

Corresponding Author: Jyotirmayee Dalai, Lecturer, Dr DY Patil Dental College and Hospital, Dr DY Patil Vidyapeth, Pune, Maharashtra, India, e-mail: jyotirmayeedalai@gmail.com
Results: Children and parents both showed a preference for bright colors in various materials and armamentarium. For materials that were to stay in a child's mouth for a long time, children still preferred colored material, whereas parents preferred tooth-colored materials. Children had an overall preference for blue color whereas parents preferred pink.

Conclusion: Introduction of more colorful and flavored restorative material as well as appliances are needed, especially for pediatric patients.

Keywords: Colors, Dental appliances, Dental materials, Flavors, Parents, Pediatric dentistry, Preventive dentistry

How to cite this article: Dalai J, Subhadra HN, Sisodia V. Colors and Flavors: Adding Joy to Pediatric Dentistry-A Crosssectional Study. J Contemp Dent 2018;8(2):63-69.

\section{Source of support: Nil}

\section{Conflict of interest: None}

\section{INTRODUCTION}

Color is one of the most instantaneous methods of conveying messages and meanings. All the existing things consist of a special property called color which together creates a colorful world. ${ }^{1}$ Color stimulates and works synergistically with all of the senses such as smell and touch, symbolizes abstract concepts and thoughts, expresses fantasy or wish fulfillment, recalls another time or place and produces an aesthetic or emotional response. ${ }^{2}$ Color has been studied from philosophical, biological, anthropological and psychological perspectives over the course of time. ${ }^{3}$ Only recently the correlation between colours and emotions and their effect on performance and productivity is being studied and adopted in the work settings. ${ }^{4}$

Most of the existing research on environmental design regarding color and structure has been focused on adults, and those findings cannot be extrapolated for children. ${ }^{5}$ A child is not a miniature of adults, and so their minds work differently too. ${ }^{6}$ The child's perception of the dental environment is a significant factor causing the anxiety. The child's dental anxiety has been of concern for many years ${ }^{7}$ and it is still a barrier to dental care. ${ }^{8}$

Recently, a study was carried out to investigate the value of color as a component of a healing environment for the pediatric patient room. ${ }^{9}$ Children can categorize colors according to several dimensions, most basic being whether a color had a positive or negative effect on their emotions or whether they found the colors to be agreeable or not agreeable. ${ }^{10}$ 
The use of child-friendly colors in the dental office that could create a positive environment for the pediatric patients has been recently studied, ${ }^{5}$ but, the application of the same in the various dental material and equipment is an area still unexplored. Colors need to be incorporated not only in the dental setups but in the armamentarium and material that are going to be in a close vision of the child, and are going to be delivered in the mouth.

Today, dental and oral care products are available in different flavors. Though, flavoring can be a marketing strategy, components do have a benefit on oral/dental tissues. Thus, it is necessary for the dental health team to advise the right flavor of products, which are palatable and equally therapeutic. Flavors are very important in a child's acceptance, as its component principally impresses the taste and smell senses. ${ }^{11,12}$

Thus the present study, first of its kind, was carried out to evaluate the patients' and parents' preference for colors and flavors in dental materials and equipment.

\section{AIM}

To assess the preference of children and parents towards conventional, colored and flavored restorative materials, appliances, and the armamentarium required for it.

\section{OBJECTIVES}

To assess the preference of children in the age group of 6 to 12 years for various colors in restorative materials, appliances, and the armamentarium.

To assess the preference of parents towards various colors in restorative materials, appliances, and the armamentarium.

\section{MATERIALS AND METHODOLOGY}

\section{Study Design and Setting}

A cross-sectional study was planned in the Department of Pediatric and Preventive Dentistry, Yerala Dental College and Hospital, Kharghar, India. The study protocol was analyzed and approved by the Institutional Review Board of Yerala Dental College and PG institution, Kharghar, India. A convenient sample was selected. Sixty children in the age group of 6 to 12 years reporting to the Department of Pediatric and Preventive Dentistry, Yerala Dental College and Hospital with their parents, formed the sample for this study.

\section{Participants}

Sixty children between the age group of 6 to 12 years and their parents consented and agreed to participate in the study.

\section{Inclusion Criteria}

The inclusion criteria were as follows:

- Children who had a physical status of ASA 1 or 2.

- Adults and children who were able to communicate in English or the local language.

\section{Exclusion Criteria}

The exclusion criteria were as follows:

- Adults or children with cognitive disability.

- Children who were unable to complete the survey independently.

- Children who were not accompanied by their parents.

\section{Study Tool}

The study tool comprised of a separate questionnaire for the parents and the children. The questionnaire was aided with a power-point presentation. For each item shown a question regarding preference was asked. The child and the parent had to independently and separately, select one most preferred option. For the questions pertaining to flavored materials, physical demonstration of materials to the participants was done. The questions were categorised under the following headings:

\section{a. Demographic Details}

- Children-Name, age, gender

- Parents-Name, age, gender

\section{b. Armamentarium related to Radiograph}

\begin{tabular}{ll}
\hline Film holders & Thyroid collars \\
\hline White & Unicolored \\
Pink & Multicolored \\
Blue & \\
Green & \\
Yellow & \\
\hline
\end{tabular}

\section{c. Armamentarium related to Isolation}

\begin{tabular}{lll}
\hline Suction tips & Cotton rolls & Mouth props/ bite blocks \\
\hline White & White & White \\
Pink & Pink & Pink \\
Blue & Blue & Blue \\
Green & Green & Green \\
Yellow & Yellow & Yellow \\
\hline
\end{tabular}

\section{d. Armamentarium for restorative procedures,} restorative material and appliances

\begin{tabular}{ll}
\hline Instruments & Steel colored \\
& Pink \\
Blue \\
Green \\
Yellow
\end{tabular}


Colors and Flavors: Adding Joy to Pediatric Dentistry-A Cross-sectional Study

\begin{tabular}{ll}
\hline Filling material & Tooth colored \\
& Pink \\
& Blue \\
& Green \\
& Purple \\
Syringes & Steel colored \\
& Transparent plastic \\
& Colourful plastic \\
Space maintainers & Steel colored \\
& Pink \\
& Blue \\
& Green \\
& Gold \\
Crowns & Steel colored \\
& White \\
& Pink \\
& Blue \\
& Green \\
& Gold \\
Orthodontic & Clear acrylic appliance \\
removable appliances & Uni-colored \\
& Multi-coloured with cartoons \\
Orthodontic fixed & Steel colored braces \\
appliances & Transparent \\
& Colored \\
\hline
\end{tabular}

\section{e. Flavoured or nonflavoured material and} armamentarium

\begin{tabular}{ll}
\hline Material & Options \\
\hline Gloves & (a) Flavored \\
& (b) Unflavored \\
Rubber dam sheets & (a) Flavored \\
& (b) Unflavored \\
Topical anesthetic gel & (a) Flavored \\
& (b) Unflavored \\
Alginate impression & (a) Flavored \\
material & b) Unflavored \\
\hline
\end{tabular}

For each item, the child/parent participant was asked to select one most preferred choice of the various options provided. For every option presented the percentage of participants who chose that option was calculated.

\section{STATISTICAL ANALYSIS}

All findings were recorded and the data was recorded in a Microsoft Office Excel (version 2013) spreadsheet. The master chart was checked for errors and discrepancies. Data analysis was done using windows based MedCalc Statistical Software version 13.3.1 (MedCalc Software bvba, Ostend, Belgium; http://www.medcalc.org; 2014). The following statistics were applied:

- Means: Average age of participants.

- Proportions: Most preferred choice.

\section{RESULTS}

The gender distribution showed that 34 (57\%) of the 60 children were boys and $26(43 \%)$ were girls. The mean age of the children was $9 \pm 0.4$.

Among the 60 parents, $40(66.6 \%)$ were mothers and $20(33.33 \%)$ were fathers. Mean age of the parents was 31 \pm 0.2 . The same is presented in Table 1 .

\section{Armamentarium related to Radiograph records (Table 2A)}

In the armamentarium related to radiograph category, the preference for colors was evaluated two items: the film holder and the thyroid collar. Of the various colors, the majority of the children preferred pink and blue most (41.6\% and $33.3 \%$ respectively), in this category. Similarly, pink and blue (58.3\% and $25 \%$ ) was preferred by parents too. About thyroid collars it was seen that children and parents both preferred multicolored items (93.3\% and 75\% respectively) as compared to uni-colored ones.

\section{Armamentarium related to Isolation (Table 2B)}

The three items evaluated under this category were cotton rolls, suction tips, mouth props or bite blocks. For suction tips and bite blocks pink was the most preferred color (41.6\% with both), whereas, for cotton rolls, blue was the choice of color by most of the children participants $(43.3 \%)$ (Table 2B).

In case of parents, for all the three items in the said category, pink was the most preferred color $(53.3 \%, 48.3 \%$ and $41.6 \%$ ), followed by blue (33.3\%, 31.6\%, and 33.3\%) (Table 2B).

\section{Armamentarium for Rrestorative Procedures, Restorative material and Appliances (Table 2C)}

In the questions related to the armamentarium for restorations such as syringes and instruments, both parents and children have not preferred the conventional steel color. Parents and children have selected blue as the best color in relation to the instrument, with $50 \%$ of children and $58.3 \%$ of parents selecting it.

In the question of syringes both the children and parents preferred colored syringes (100\% and 83.3\% respectively).

Majority of the child participants' preferred colored restorations of which blue was the most preferred color (43.33\%). Only $10 \%$ of children preferred white restorations. On the contrary, $51.6 \%$ of parents preferred toothcolored restorations.

About crowns, $41.6 \%$ of children said they would prefer blue colored crowns as compared to all the other options. Parents on the other hand preferred toothcolored crowns, with $63.3 \%$ of parents choosing it over the other crown options.

In the question related to space maintainers, parents preferred pink colored space maintainers (41.6\%), whereas children preferred the blue colored ones (41.6\%). 
Table 1: Presents demographic distribution of the child participants and parents.

\begin{tabular}{|c|c|c|c|c|c|}
\hline \multirow[t]{2}{*}{ Children } & Gender & Male & $34(57 \%)$ & Age & \\
\hline & & Female & $26(43 \%)$ & & \\
\hline \multirow[t]{2}{*}{ Parents } & Gender & Male & $20(33.3 \%)$ & 6 to 9 years & $42(70 \%)$ \\
\hline & & Female & $40(66.6 \%)$ & 9 to 12 years & $18(30 \%)$ \\
\hline
\end{tabular}

Table 2: Presents the distribution of responses of the child participants.

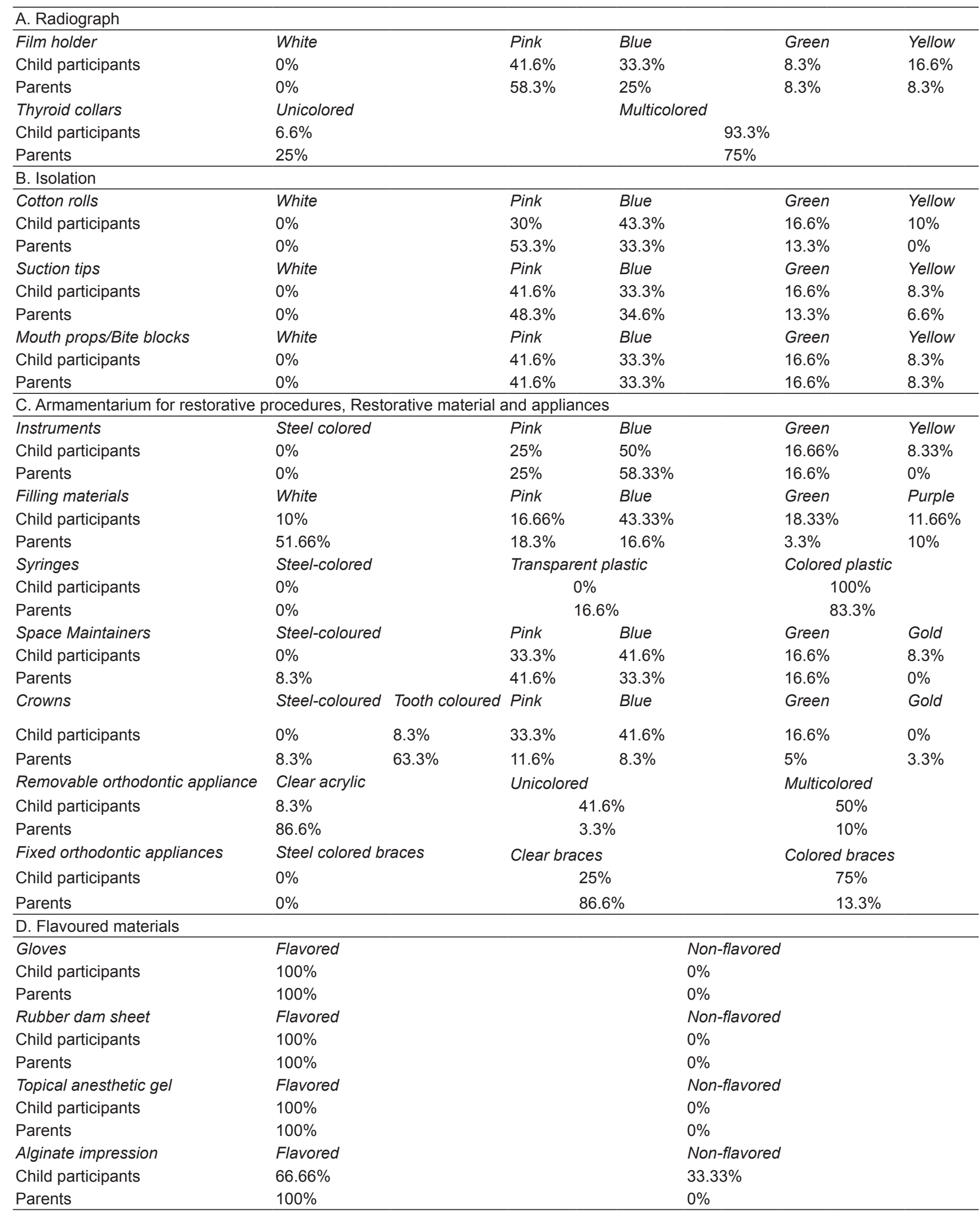


In the removable orthodontic appliance, while the children preferred more colorful, multi-colored appliances $(50 \%)$, parents preferred the transparent clear acrylic ones (86.6\%).

Similarly, for fixed appliances children preferred colored braces $(75 \%)$ as compared to parents who chose clear or tooth-colored braces (86.6\%).

\section{Flavors (Table 2D)}

In the category of questions related to the use of flavored materials, all the parents $(100 \%)$ preferred the use of flavored material. In the group of children, all children liked the flavored material in the items such as gloves, rubber dam sheets, and topical anesthetic gel. (100\%) But, in the question related to alginate impression material, while $66.6 \%$ preferred the flavored type, the others liked the unflavored type.

\section{DISCUSSION}

Gender distribution: The gender distribution showed that $57 \%$ of the children were boys and $43 \%$ were girls. The unequal distribution between the genders could have made a difference to the results as it is well documented that girls and boys have different color preferences. ${ }^{13-15}$

Among the 60 parents, 40 (66.6\%) were mothers, and $20(33.33 \%)$ were fathers, which again may have affected the results. ${ }^{7,8}$

\section{Armamentarium Related to Radiograph}

All the children participants preferred bright colors over white. These findings are in accordance with previous studies. ${ }^{9,16}$ Similarly, parents too showed a preference for colors other than white for their kids. This possibly could be because the white color is associated with the medical profession and may elicit fear and apprehension in a child's mind. . $^{17,18}$

\section{Armamentarium Related to Isolation}

In armamentarium used for isolation, the majority of children chose the blue colour as their favorite, while the parents chose pink. This possibly could be because $66.6 \%$ of the parents were mothers. Women have been reported to prefer the color pink over blue when the two were presented as options. The color is associated with feminity and hence usually preferred by women of all ages. ${ }^{19-21}$ Armamentarium for restorative procedures, restorative material, and appliances

Regarding armamentarium, children and the parents seem to be following both preferring the coloured options rather than the conventional one. This possibly could be due to the anxiety associated with the appearance of the conventional metal and transparent plastic syringes the children are used to.

Blue was seen to be the more common choice for children, whereas parents favored pink. A majority of parents preferring pink could be because of the gender distribution with $66.6 \%$ of the parents being mothers. ${ }^{19-21}$ This was as per with the previous studies. ${ }^{5,13,22,23}$

On the contrary, in the questions related to restoration filling material, crowns, orthodontic removable and fixed appliances, while children preferred bright colors, parents chose tooth colored and transparent options over the colored ones. This could be because parents are used to the conventional material and perceive it to be tooth colored, more natural and so better for the child, whereas children tend to like bright colors. ${ }^{13,15,16}$

Overall, children and parents both have preferred brighter colors for use in armamentarium and materials used in dentistry. For restorations and appliances that are going to remain for long in the child's mouth, children have still preferred bright colors such as blue and pink, or multicolors, whereas parents have preferred tooth colored, white or clear options.

These findings are previous studies where children, in general, have preferred bright colors. Blue is seen to be the favorite color among young children along with pink, green and yellow. ${ }^{5,24,25}$ Similar results were reflected in the present study. Blue and pink were the preferred choices as they are associated with happy and joyful emotions. ${ }^{5,24,25}$ Although yellow is a particular favorite among the very young children, and it was not selected by children in the present study probably because the majority of the participants were more than 6 years of age, when yellow is no more a choice of the child..$^{5,26}$ The color green was probably not selected by the children and parents probably because, like white, green too is associated with hospital environments. ${ }^{27-29}$

\section{Flavors}

In the category of questions related to the use of flavored materials, all the parents $(100 \%)$ and most of the children preferred the use of flavored materials except for alginate impression material where $33.3 \%$ of the children preferred a non-flavored material. This possibly could be because the strong smell of the flavur could add to a child's natural gag reflex. . $^{30,31}$

Use of flavors is important in dentistry, as it is a well-known fact that dental flavors provide taste benefits and freshen breath, mainly by sensorial masking 
primarily by mechanochemical cleaning or by active antimicrobial systems by inhibiting bacterial volatile sulfide compound production. It is also postulated that flavonoids and the related compounds added for flavors in various agents have therapeutic benefits, i.e., anti-inflammatory, antifungal, bacteriostatic, antithrombotic, anti-oxidant, and sometimes immunostimulant action. ${ }^{32,33}$ Also, inputs received through the sensory systems, individually or together, can produce emotion and influence cognition. Also, odors influence autonomic responses, for example, pleasant and novel odors can decrease heart rate. ${ }^{32,33}$ Also, overall, flavored material were favored possibly because of the feeling freshness and taste benefits of it. $12,34,35$

\section{Limitations}

The past dental experience of the children and parents could not be assessed. Apart from the child's personality, his or her previous experiences may also have played a crucial role in the child's development of likings and also have affected the child's level of dental fear. The questionnaire in this study did not evaluate these factors.

A child's choice recorded at a particular point in time may be affected by his or her mood, and need not reflect permanent liking for the color. But the consistent selection of colors of a similar kind for all items reflects a preference. In this study, all children preferred bright colors over dull or white.

The choices made were based on the two dimensional images showed through the PowerPoint presentation. The actual color in real clinical situations may vary, and thus the preference could be different too.

It may also be of value to evaluate longitudinally in future studies, the effect and pattern of color and flavor preferences at different stages of growth, the difference in choices between genders, and its association with the child's emotions.

\section{Generalizability}

The results of this study are generalizable in children of age-group of 6 to 12 years in a similar setting.

\section{CONCLUSION}

Children, as well as parents, have a preference for bright colors such as pink and blue as compared to the conventional white and green used in instruments, armamentarium, and materials.

For restorative materials and appliances, while children still prefer bright colors, parents have preferred clear and tooth-colored material.

\section{REFERENCES}

1. Mohebbi M. Investigating the gender-based colour preference in children. Procedia Soc Behav Sci. 2014;112:827-31.

2. Ulrich RS. Nature verses urban scenes; some psychological well-being. Environ Behav. 1981;13:523-556.

3. Saunders B. What is colour? (Man's perception of colours). Br J Psychol. 1998;89:697-704.

4. Cimbalo RS, Beck KL, Sendziak DS. Emotional toned pictures and color selection for children and college students. J Gen Psychol 1978;133:303-304.

5. Umamaheshwari N, Asokan S, Kumaran TS. Child friendly colors in a pediatric dental practice. J Indian Soc Pedod Prev Dent. 2013;31:225.

6. Armsden GC, Greenberg MT. The inventory of peer and parent attachment: individual differences and their relationship to psychological well-being in adolescence. J Youth Adolesc. 1987;16:427-454.

7. Steen WM. Our relation to children. Dent Rev 1891;5:534-7.

8. Nuttall NM, Bradnock G, White D, Morris J, Nunn J. Dental attendance in 1998 and implications for the future. Br Dent J 2001;15:357-387.

9. Park JG. Color perception in pediatric patient room design: Healthy children vs. pediatric patients. HERD. Health Environments Research and Design Journal. 2009;2:6-28.

10. Terwogt MM, Hoeksma JB. Colors and emotions: Preferences and combinations. J Genet Psychol .1995;122:5-7.

11. Kanny G, Hatahet R, Moneret-Vautrin DA, Kohler C, Bellut A. Allergy and intolerance to flavoring agents in atopic dermatitis in young children. Allerg Immunol. 1994;26:204-206

12. Cugati N. Is flavor component in dental product therapeutic? Dent Res J. 2012;9:119.

13. McMurtry CM, Noel M, Taddio A, Antony MM, Asmundson GJ, Riddell RP, Chambers CT, Shah V. Interventions for individuals with high levels of needle fear: systematic review of randomized controlled trials and quasi-randomized controlled trials. Clin J Pain. 2015;31 (Suppl 10):S109.

14. Birren F. Aspects of light and color bearing on the reactions of living things and the welfare of human beings. In: Birren F, editor. Color and Human Response. 1 st ed. New York: Van Nostrand Rein-hold; 1978. p. 30.

15. Wexner LB. The degree to which colors (hues) are associated with mood-tones. J Appl Psychol. 1954;6:432-436.

16. Lawler CO, Lawler EE. Color-mood association in young children. J Gen Psychol. 1965;107:29-32.

17. Farraj R, Baron JH. Why do hospital doctors wear white coats? J R Soc Med. 1991;84:43-46.

18. Fernandes E. Doctors and medical students in India should stop wearing white coats. BMJ: British Medical Journal (Online). 2015;21:351.

19. Ellis L, Ficek C. Color preferences according to gender and sexual orientation. Personality and Individual Differences 2001;31:1375-1379.

20. Al-Rasheed AS. An experimental study of gender and cultural differences in hue preference. Front Psychol. 2015 ; 30:6:30.

21. Wong WI, Hines M. Preferences for pink and blue: The development of color preferences as a distinct gender-typed behavior in toddlers. Arch Sex Behav. 2015;44:1243-1254.

22. Carruthers HR, Morris J, Tarrier N, Whorwell P. The Manchester color wheel: Development of a novel way of identifying color choice and its validation in healthy, anxious and depressed individuals. BMC Med Res Methodol. 2010;10:1-16. 
23. Schaie KW. Scaling the association between colors and moodtones. Am J Psychol. 1961;74:266-273.

24. Goethe. Effect of colours with reference to moral association. In: Eastlake CL, editor. Theory of Colours. 2nd ed. Cambridge, MA: MIT Press; 1840. p. 321-323.

25. Odom AS, Sholtz SS. The reds, whites, and blues of emotion: Examining colour hue effects on mood tones. National Undergraduate Research Clearinghouse. Available from: http://www.webclearinghouse.net/volume/ [Last retrieved on 2018 May 18].

26. Fleming, JW, Holmes, S, and Barton, L Differences in Color Preferences of School-age Children in Varying Stages of Health: A Preliminary Study. Maternal-Chil dNursing Journal. 1988;17(3):173-189.

27. Pantalony D. The colour of medicine. Canadian Medical Association Journal. 2009;181:402-403.

28. Colour in Hospital Rooms. Canadian Medical Association Journal. 1945;52:104.

29. Reiling J. Safe design of healthcare facilities. BMJ Quality and Safety. 2006;1;15(suppl 1):i34-40.
30. Nandini VV, Venkatesh KV, Nair KC. Alginate impressions: A practical perspective. J Conserv Dent. 2008;11:37-41.

31. Hattab FN, Al-Omari MA, Al-Duwayri ZN. Management of a patient's gag reflex in making an irreversible hydrocolloid impression. J Prosthet Dent. 1999;81:369.

32. Fletcher M, Wilson DA Ontogeny of odor discrimination: a method to assess novel odor discrimination in neonatal rats. Physiol. Behav. 2001;74:589-593.

33. Lehrner J, Eckersberger C, Walla P, Potsch G, Deecke L. Ambient odor of orange in a dental office reduces anxiety and improves mood in female patients. Physiol. Behav. 2002; 71: 83-86.

34. Bradshaw DJ, Perring KD, Cawkill PM, Provan AF, McNulty DA, Saint EJ, Richards J, Munroe MJ, Behan JM. Creation of oral care flavours to deliver breath-freshening benefits. Oral diseases. 2005;11(s1):75-79.

35. Deepika A, Chandrasekhar Rao R, Vinay C, Uloopi KS, Rao VV. Effectiveness of two flavored topical anesthetic agents in reducing injection pain in children: a comparative study. J Clin Pediatr Dent. 2012;37:15-18. 